\title{
AVALIAÇÃO DA PRESENÇA DA SUSTENTABILIDADE AMBIENTAL NO ENSINO DOS CURSOS DE GRADUAÇÃO DA UNIVERSIDADE DE PASSO FUNDO
}

\author{
LUCIANA LONDERO BRANDLI*1 \\ Marcos Antonio Leite Frandoloso** \\ KÉllen Tolotti Fraga*** \\ Letícia CANAL VIEIRA**** \\ LUIS AdRIEL PEREIRA*****
}

Recebido: 16 jun. 2011

Aprovado: 27 mar. 2012

\begin{abstract}
* Doutora em Engenharia de Produção. Professora adjunto III da Universidade de Passo Fundo, atua no Programa de Pós-graduação em Engenharia, Infraestrutura e Meio ambiente. Passo Fundo, RS. E-mail: brandli@upf.br

**Mestre em Arquitetura. Doutoramento na Universitat Politècnica de Catalunya, Barcelona, Espanha. Professor Adjunto I da Universidade de Passo Fundo. Passo Fundo, RS. E-mail: frandoloso@upf.br

*** Graduada em Ciências Biológicas LP/B. Mestranda do Programa de pós graduação em Engenharia, com área de concentração Infraestrutura e meio Ambiente da Universidade de Passo Fundo. Passo Fundo, RS. E-mail: kellenfraga@yahoo.com.br

***** Acadêmica do curso de Engenharia Ambiental, Faculdade de Engenharia e Arquitetura, Universidade de Passo Fundo. Bolsista FAPERGS e pesquisadora na área de gestão de projetos ambientais. Passo Fundo, RS. E-mail: 79117@upf.br

***** Acadêmico do Curso de Engenharia Ambiental, Faculdade de Engenharia e Arquitetura, UPF. Bolsista de Iniciação Científica da Universidade de Passo Fundo. Passo Fundo, RS. E-mail: 69036@upf.br
\end{abstract}

Resumo: As Instituições de Ensino Superior (IES) são cada vez mais responsáveis por disseminar mudanças em prol da sustentabilidade seja por meio do ensino, pesquisa, extensão ou sua forma de operação, e a necessidade de avaliar a efetividade destas mudanças se faz necessária, para que estas IES sirvam de modelo e inspirem outras instituições. O AISHE é um instrumento desenvolvido especificamente para avaliar a sustentabilidade ambiental nas IES e é por meio desse tipo de metodologia, baseada em indicadores, que se pode afirmar se as práticas adotadas estão sendo efetivas. Este artigo apresenta a aplicação desta ferramenta na Universidade de Passo de Fundo. A pesquisa seguiu as etapas: adaptação do método, aplicação da ferramenta para coordenadores, estudantes e professores, construção de gráficos, cálculo de medianas e analise dos resultados. Os resultados mostraram significantes diferenças entre os cursos, demonstrando falta de visão estratégica e de gestão da universidade. No entanto, existem critérios que poderiam ter sido avaliados mais positivamente para todos, se houvesse um planejamento da universidade que definisse nos cursos meios para aprimorarem a sua sustentabilidade ambiental. Dessa forma a existência de uma política e gestão ambiental adequada se faz necessária para que a sustentabilidade seja inserida de forma eficaz no ensino da instituição.

Palavras-chave: Desenvolvimento sustentável. AISHE. Universidades. Educação.

1 Agradecimentos: ao CNPQ pelo apoio financeiro ao projeto, pela bolsa produtividade pesquisa e pela bolsa de iniciação científica, à FAPERGS pela bolsa de iniciação científica e as unidades acadêmicas da Universidade de Passo Fundo que participaram do estudo. 
EVALUATION OF THE PRESENCE OF ENVIRONMENTAL SUSTAINABILITY IN THE EDUCATION OF UNDERGRADUATE PROGRAMS AT THE UNIVERSITY OF PASSO FUNDO

Abstract: Higher Education Institutions (HEI's) are becoming more and more responsible for disseminating changes in favor of sustainability, either through teaching, research, extension or its form of operation, and it has therefore become necessary to evaluate the effectiveness of these changes, so that these HEI's may act as models to other institutions. The AISHE is a device developed specifically to evaluate environmental sustainability in HEI's and it is through this kind of methodology, based on indicators, that it is possible to affirm if the adopted practices are indeed effective. This article presents the application of this tool at the University of Passo Fundo. The research followed these steps: adaptation of the method, application of the tool to coordinators, students and teachers, building of graphs, calculation of median and results analysis. The results showed significant differences between the programs, demonstrating a lack of strategic and managerial vision on the part of the university. On the other hand, there are criteria that could be evaluated more positively for all, if there were a university plan that defined for the programs ways to enhance their environmental sustainability. In this way the existence of an environmental policy and management becomes necessary for sustainability to be effectively inserted in the institution's teaching programs.

Key words: Sustainable development. AISHE. Universities. Education.

\section{INTRODUÇÃO}

O papel das Instituições de Ensino Superior (IES) frente aos desafios da gestão ambiental vem ganhando cada vez mais destaque nos últimos anos. Isto se deve as estruturas cada vez mais complexas de seus campi, com inputs e outpus, que demandam uma gestão ambiental, ou ao menos, ações voltadas à eficiência do uso dos recursos. Aliado a isto, o papel social que as Instituições de ensino desempenham, disseminador de conhecimento, e formador do tomador de decisão do futuro nas mais variadas áreas, tornando-se responsável pela implementação da consciência sustentável na sociedade (TAUCHEN; BRANDLI, 2006; HALAC; SCHILLER; VENTURINI, 2005; ROORDA, 2008).

Observa-se, contudo, que as IES não estão imunes à morosidade do processo de firmamento desta nova consciência. As barreiras enfrentadas para que se incorpore uma consciência sustentável no ambiente das IES muitas vezes passam pelo crivo do pensamento de que o desenvolvimento sustentável (DS) é apenas uma moda, ou que o confunde como sendo relativo apenas as questões ambientais. Essa dificuldade de entendimento do que é DS muitas vezes está presente na alta administração das instituições, fazendo com que questões essenciais relacionadas à sustentabilidade não recebam a atenção necessária devido à burocracia, sendo tratadas como apenas mais um processo administrativo, limitado pelos interesses econômicos. Para Velasquez et al (2006), o 
que falta é uma orientação clara e objetiva sobre o que exatamente deve ser a sustentabilidade nas IES.

Segundo Brandli et al (2010) o sistema burocrático e hierárquico rígido; a falta de conscientização e comprometimento dos agentes envolvidos (docentes, discentes e administração); e a inexistência de definição de políticas institucionais de curto e longo prazo são entraves comuns encontrados nas universidades que as impedem de avançar em aspectos como a gestão ambiental de seus campi.

Diversas IES vêm discutindo o conceito de "universidade sustentável", e o que se observa é que existem muitas maneiras de integrar a prática da sustentabilidade na sua política universitária, organização e atividades. As universidades podem, por exemplo, envolver-se com o DS no seu planejamento, gerenciamento, educação, pesquisa, operações, serviços comunitários, aquisição de materiais, transporte e infraestrutura (WEENEN, 2000).

Segundo García (2006) o sistema universitário, de modo geral, é básico e está dividido em cinco dimensões: a Educação (cursos e currículos), Pesquisa (básica e aplicada), as operações do campus, extensão comunitária e avaliação e comunicação, sendo que estas dimensões são interdependentes. Para o autor ora mencionado, o ideal seria que os preceitos do DS atingissem a toda a comunidade acadêmica de maneira sistêmica, porém, na prática o que ocorre é uma a incorporação fragmentada. Weenen (2000) complementa essa ideia, ao afirmar que essas abordagens sobre a sustentabilidade nas IES vêm ocorrendo de muitas formas e isto varia de acordo com os seus objetivos. Algumas instituições têm conseguido seguir planos de ação para promover com sucesso iniciativas de sustentabilidade.

Neste contexto, torna-se importante a medição, através de indicadores, do envolvimento da universidade com a sustentabilidade a partir do desenvolvimento de um quadro geral que possibilite avaliar sua situação atual ou progresso. Estes indicadores, no entanto, devem ser instrumentos adequados as particularidades das Instituição de ensino superior, a exemplo do Auditing Instrument for Sustainability in Higher Education (AISHE), desenvolvido especialmente com esta finalidade.

Em 2008, a Universidade de Passo Fundo (UPF) comprometeu-se em participar do grupo de universidades que aplicariam a ferramenta AISHE em seus ambientes internos e externos, juntamente com outras universidades de diversos países. O objetivo deste artigo é avaliar a sustentabilidade ambiental dos cursos de graduação da UPF, tornando possível identificar prioridades no que tange a busca pela sua sustentabilidade ambiental. 


\section{REVISÃO BIBLIOGRÁFICA}

\subsection{Instrumentos para avaliação da sustentabilidade}

Na inclusão da sustentabilidade no ensino superior as instituições devem atuar como agentes de mudança. Segundo Adomssent, Godemann e Michelsen (2007), é necessário saber diferenciar as instituições que aceleram essa inclusão e as que bloqueiam esse processo. Nessa linha é importante que as instituições disseminem as mudanças implantadas em prol da sustentabilidade e avaliem a efetividade destas, servindo de modelo e inspirando outras, atuando como um acelerador. Para mensurar essa efetividade são necessários instrumentos que avaliem a sustentabilidade nas instituições de ensino superior e apresentem dados concretos, fazendo o uso de indicadores.

A razão mais corriqueira para se utilizar um instrumento de avaliação da sustentabilidade no ensino superior é obter informações sobre a situação da instituição que colaborem para a gestão e formulação de uma política. Essas informações também podem ser utilizadas para incluir elementos da sustentabilidade diretamente na educação e pesquisa, e para avaliar a política dos anos passados (ROORDA; MARTENS, 2008).

Essa avaliação ainda permite a identificação de práticas de sucesso que devem ser divulgadas e possui uma grande importância interna. Por meio da avaliação as fraquezas são identificadas e as mudanças que são necessárias acabam transparecendo. Dessa forma novas ações podem ser tomadas para melhorar a questão da sustentabilidade dentro da instituição. Conseqüentemente esses resultados vão possibilitar a construção de relatórios e reportar esses resultados é importante por três motivos "(i) informar a sociedade do progresso do plano ambiental da instituição; (ii) a instituição demonstra sua preocupação com o meio ambiente [...]; (iii) ajudar a manter uma base de dados sobre programas de gestão ambiental" (FERREIRA; LOPES; MORAIS, 2006). Essa comunicação é a chave para o sucesso de todos na busca dessa meta ambiciosa que é a sustentabilidade no ensino superior (SHRIBERG, 2002).

No momento em que o objetivo principal da inclusão da sustentabilidade nas instituições (seja por meio de um sistema de gestão ambiental ou da inserção direta do tema no currículo) é que os estudantes atuem em prol da sustentabilidade, precisa-se avaliar a efetividade dessas ações. É necessário dimensionar sua influência, se elas estão de fato contribuindo para formação dos valores dos estudantes e construção de uma nova visão em relação ao meio ambiente. Isso demonstra outro papel importante que ferramentas de avaliação devem atender. 
Seus indicadores devem ter a capacidade de medir o conhecimento e comprometimento dos estudantes frente à sustentabilidade. Três pilares básicos devem ser observados quando se procura criar indicadores para medir a efetividade da inclusão da sustentabilidade no ensino, sendo eles o conhecimento, a boa vontade e a capacidade dos alunos em relação ao desenvolvimento sustentável (LIDGREN; RODHE; HUISINGH, 2006).

Buscando definir uma ferramenta ideal para avaliação da sustentabilidade no ensino superior Shriberg (2002), elencou as principais características que um instrumento deve conter, são elas:

- As ferramentas devem identificar questões de larga escala e influência, permitindo ainda medidas específicas. Além disso, devem fornecer mecanismos para que seja possível priorizar questões.

- As ferramentas devem ser flexíveis para capturar as complexidades e diferenças da organização, bem como seu progresso em direção à sustentabilidade, algo possibilitado pelos critérios qualitativos. Porém devem ser suficientemente específicas para que possam ser calculadas e comparadas, característica dos critérios quantitativos.

- A distinção é crucial já que indicadores de eco-eficiência medem a utilização de materiais, desempenho ambiental e cumprimento legal, enquanto os indicadores de sustentabilidade abordam a interação entre o ambiente, sociedade e economia visando o impacto zero (O`CONNOR, 1995 apud SHRIBERG, 2002).

- Para identificar os agentes de mudança na organização, as ferramentas devem questionar "por que" e "como" as instituições buscam a sustentabilidade, além do “o quê” vem sendo feito.

- As ferramentas de avaliação devem ser compreensíveis para a maioria dos atores envolvidos. A compreensibilidade não deve ser sacrificada pela precisão.

\subsection{Instrumento para avaliação da sustentabilidade no ensino superior}

O Auditing Instrument for Sustainability in Higher Education (AISHE) é um instrumento voltado especificamente para avaliar a sustentabilidade nas 
instituições de ensino. A Fundação Européia para a Gestão de Qualidade desenvolveu um modelo chamado EFQM, que utiliza como base o Circulo de Qualidade Deming, também conhecido como o ciclo PDCA. Nas fases Planejar, Fazer, Verificar e Agir foram incluídos um número de critérios, que atuam como indicadores, e dizem respeito à qualidade de gestão da companhia. A Organização Holandesa para Gestão de Qualidade, INK, melhorou o modelo EFQM acrescentando para cada critério uma escala ordinal de cinco estágios. Cada estágio é uma descrição verbal de um possível estado em que a companhia avaliada está a respeito de um critério (AISHE, 2001; ROORDA, 2008).

A partir do modelo-EFQM-INK, um grupo de universidades holandesas adaptou uma versão para o Ensino Superior, gerando o modelo-EFQM-HE, que foi usado como base para o desenvolvimento do AISHE. Os critérios do AISHE atuam como indicadores, facilitando a compreensão de uma determinada situação e possibilitando a comparação com uma situação futura desejada. O AISHE é tanto um método de auditoria quanto um instrumento que pode ajudar a formular políticas, igualmente como a ISO 14001 (SHRIBERG, 2002). Conforme demonstra o Quadro 1, o AISHE está baseado no ciclo PDCA (planejar, fazer, verificar e agir), sendo que dentro de cada uma das fases do ciclo são avaliados campos de atenção, cada um com quatro critérios. Uma breve descrição dos campos de atenção está apresentada no Quadro 2.

\section{Quadro 1 - Instrumento de avaliação AISHE}

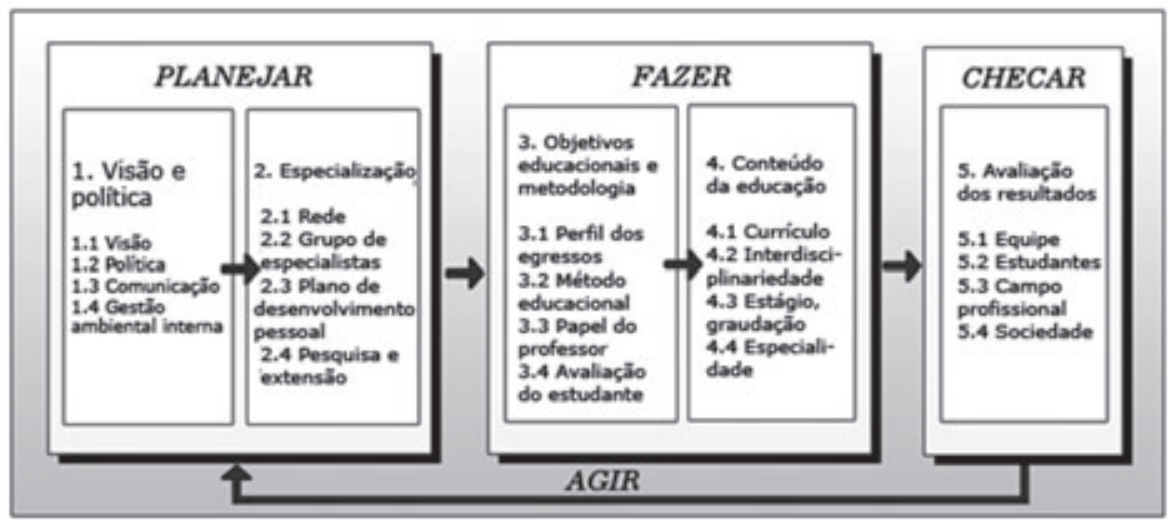

Fonte: Adaptado de AISHE (2001). 


\section{Quadro 2 - Descrição dos campos de atenção AISHE.}

\begin{tabular}{|l|l|}
\hline Campo de Atenção & Descrição \\
\hline Visão e Política & $\begin{array}{l}\text { Refere-se ao planejamento, definição de metas e formulação de } \\
\text { documentos, visando à sustentabilidade, bem como a existência de } \\
\text { uma gestão ambiental. }\end{array}$ \\
\hline Especialização & $\begin{array}{l}\text { Está relacionado a preparação da organização no que diz respeito } \\
\text { ao desenvolvimento sustentável, abrangendo toda a comunidade } \\
\text { acadêmica. Esse campo apresenta a necessidade de um grupo } \\
\text { de especialistas em sustentabilidade e a presença desse tema nos } \\
\text { programas de pesquisa e extensão. }\end{array}$ \\
\hline $\begin{array}{l}\text { Objetivos } \\
\text { Metodocionais e }\end{array}$ & $\begin{array}{l}\text { Refere-se a maneira como o tema da sustentabilidade é abordado } \\
\text { pela organização e se essa abordagem é significativa para gerar a } \\
\text { preocupação com a sustentabilidade no exercício profissional dos } \\
\text { egressos. }\end{array}$ \\
\hline $\begin{array}{l}\text { Conteúdo da } \\
\text { Educação }\end{array}$ & $\begin{array}{l}\text { Avalia a existência do tema sustentabilidade no currículo e a } \\
\text { possibilidade de adquirir maior conhecimento a respeito. Também } \\
\text { aborda se o posicionamento do estudante é voltado à sustentabilidade } \\
\text { na tomada de decisões. }\end{array}$ \\
\hline $\begin{array}{l}\text { Avaliação dos } \\
\text { Resultados }\end{array}$ & $\begin{array}{l}\text { Procura observar a existência de dados sobre a avaliação feita pelos } \\
\text { estudantes, equipe, campo profissional e sociedade, a respeito da } \\
\text { política de sustentabilidade. E a possibilidade de se fazer comparaçães } \\
\text { desses dados com os de outras organizações que são referencia em } \\
\text { sustentabilidade. }\end{array}$ \\
\hline
\end{tabular}

Os critérios podem ser classificados de acordo com cinco estágios (nível de sustentabilidade): Estágio 1: atividade (separado em partes); Estágio 2: processo (único processo); Estágio 3: sistema (processo com feedback); Estágio 4: rede (parte de uma rede de processos); Estágio 5: sociedade (parte da sociedade). Cada estágio respeita uma escala ordinal para as cinco fases. Sendo assim, só é permitido concluir que um determinado estágio foi alcançado, se as fases anteriores forem atingidas em sua plenitude, pois todas as etapas de um critério são destinadas a serem cumulativas. Por isso, podem-se definir valores intermediários $(1,5 ; 2,5 ; 3,5 ; 4,5)$ para cada critério.

Segundo Shriberg (2002), o AISHE é um excelente exemplo de abordagem que possibilita avaliar a sustentabilidade a partir de indicadores com orientação. A meta vinculada a criação do AISHE foi a de construir uma plataforma flexível onde é possível estimular e operacionalizar a sustentabilidade no ensino superior. Por fim, o AISHE tem potencial para um alcance e apelo global. Apesar disto, o autor salienta ainda um ponto fraco da ferramenta AISHE, onde seus critérios são abstratos e difíceis de compreender. Além disso, o AISHE não inclui explicitamente indicadores sobre motivações para a busca da sustentabilidade. Em outras palavras, é possível usar a ferramenta sem deixar claras as razões de buscar a sustentabilidade. 


\section{MÉTODO DE PESQUISA}

Este estudo foi desenvolvido no campus I da Universidade de Passo Fundo, localizada na região norte do Rio Grande do Sul, uma universidade de caráter comunitária, com cerca de 20 mil alunos, 1000 professores, 1000 funcionários, distribuídos em 7 campi, com 54 cursos de graduação, 7 cursos técnicos, 45 cursos de especialização, 7 mestrados e 1 doutorado. O foco do estudo foram os 40 cursos de graduação da instituição, dos quais participaram da pesquisa 30 cursos, o que representa $75 \%$ da população foco, uma vez que nesta etapa da pesquisa não foram incluídos os 14 cursos superiores de formação tecnológica.

A pesquisa foi realizada de acordo com o delineamento da Figura 1:

Figura 1 - Organograma da pesquisa.

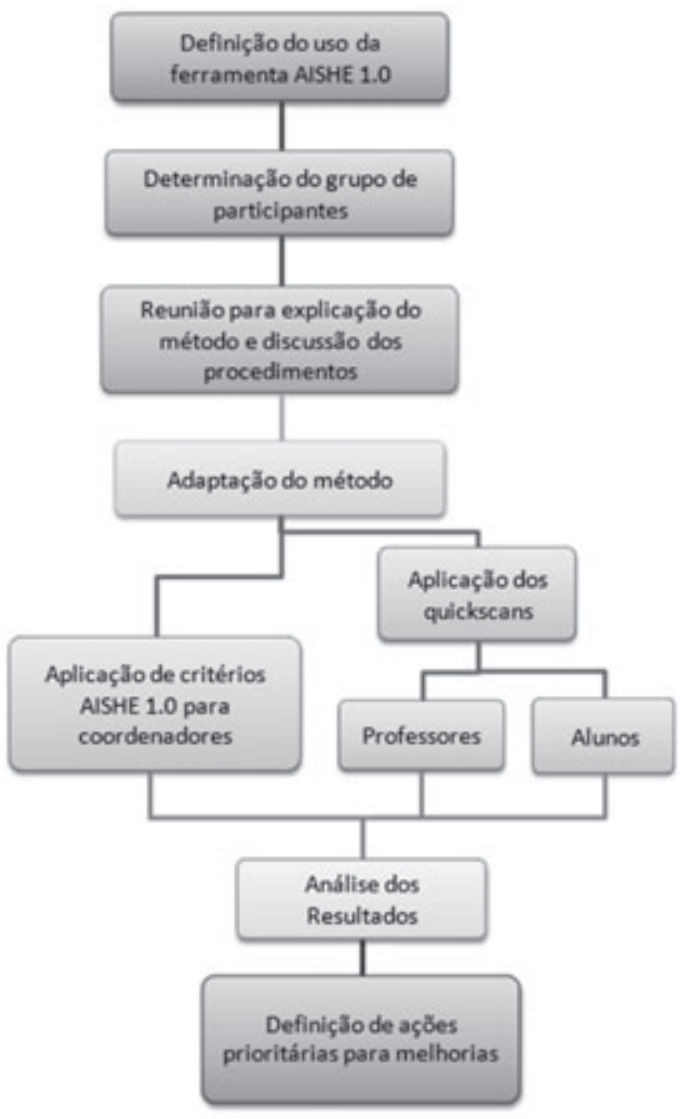


A metodologia AISHE foi aplicada para os coordenadores dos cursos de graduação, partindo-se do pressuposto que estas seriam as pessoas mais indicadas para responderem por seus cursos, pois estão envolvidos diretamente nas atividades cotidianas dos mesmos e os conhecem em maior profundidade. Os critérios estabelecidos na avaliação AISHE foram respondidos individualmente pelos coordenadores, com o auxílio de tabelas explicativas para cada critério, podendo enquadrá-los de acordo com um dos estágios possíveis. Para a apreciação dos resultados a metodologia AISHE permite fazer uso da mediana das pontuações.

Posteriormente, foi realizado um quickscan, na forma de um questionário, para professores e alunos, com o objetivo de triangular os dados obtidos com os coordenadores. Este questionário também faz parte da metodologia AISHE, consistindo em nove aspectos referentes a sustentabilidade e que se relacionam com os critérios respondidos pelos coordenadores. No total, participaram 60 professores e 90 alunos dos 30 cursos.

\section{ANÁLISE DOS RESULTADOS}

\subsection{Avaliação da sustentabilidade segundo os coordenadores}

O Quadro 3 apresenta o nível de sustentabilidade atribuído pelos coordenadores a cada um dos critérios quando avaliada a situação do seu curso. Apresentam-se ainda as medianas dos cursos, dos critérios e dos campos de atenção, todas elas analisadas na sequência.

Na Figura 2 são apresentados os resultados das medianas dos cursos, onde se pode observar que estes apresentam diferentes níveis de sustentabilidade. Alguns atingiram níveis considerados elevados (estágio 4 e 5), porém, percebe-se que estes são exceções, haja vista que $53,4 \%$ dos cursos avaliados enquadraram-se no Estágio 1, demonstrando falta de visão estratégica e de gestão universitária que abranja um comportamento uniforme em todos os cursos.

A Figura 3 resulta da mediana de cada critério em relação às pontuações atribuídas pelos cursos avaliados. O critério metodologia educacional (3.2) foi o que mais se destacou, atingindo o Estágio 3, o que significa que a metodologia de ensino e aprendizagem proporciona ao estudante deparar-se com situações reais, que possibilitam a reflexão sobre o desenvolvimento de sua atividade profissional futura de maneira sustentável. 
Luciana Londero Brandli; Marcos Antonio Leite Frandoloso;

Kéllen Tolotti Fraga; Letícia Canal Vieira; Luis Adriel Pereira

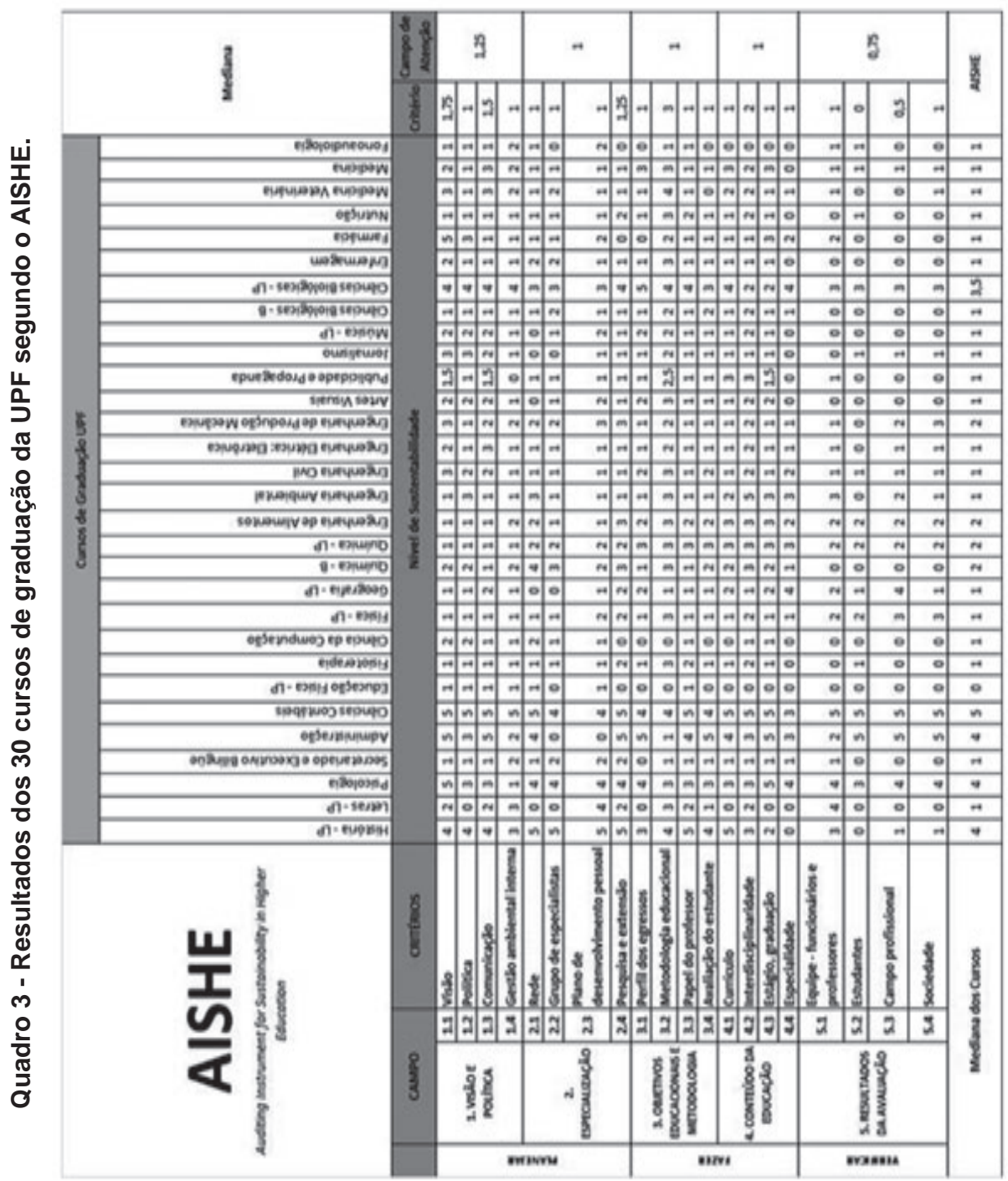


Figura 2 - Gráfico das medianas dos cursos de graduação.

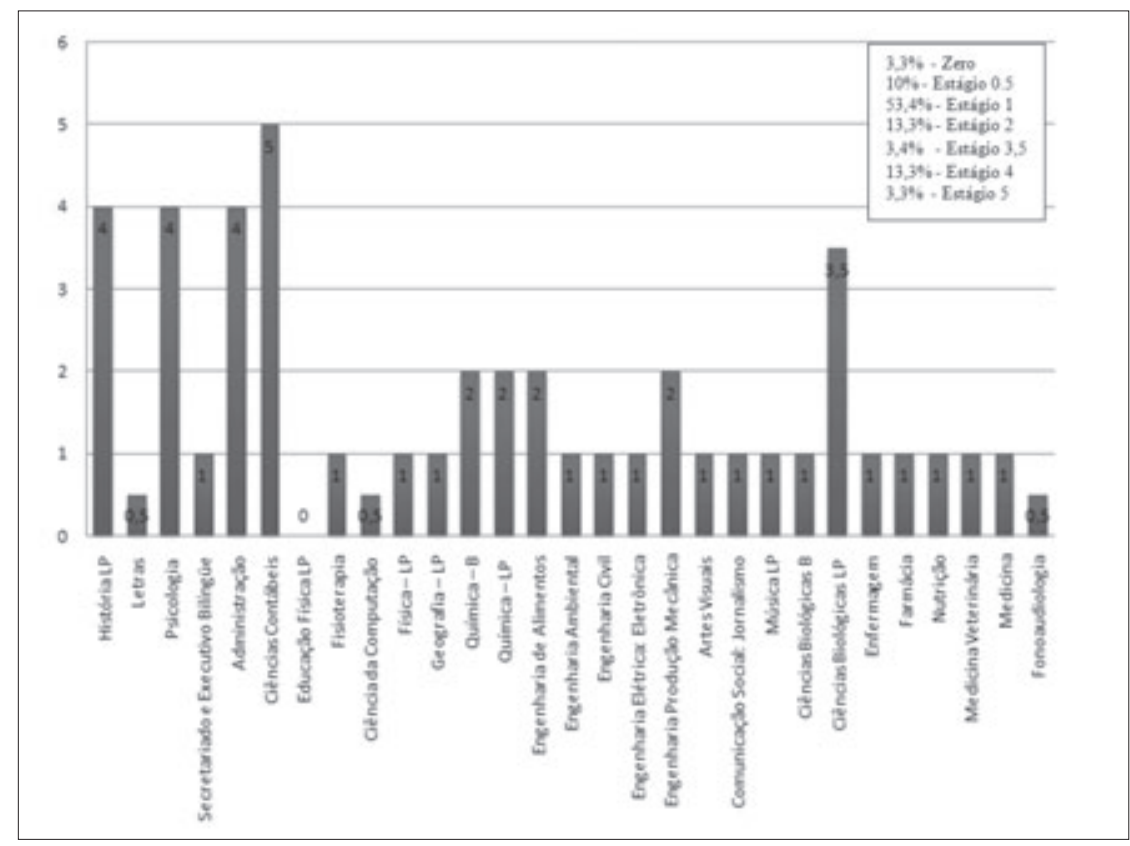

Figura 3 - Mediana do nível de sustentabilidade dos critérios da avaliação AISHE.

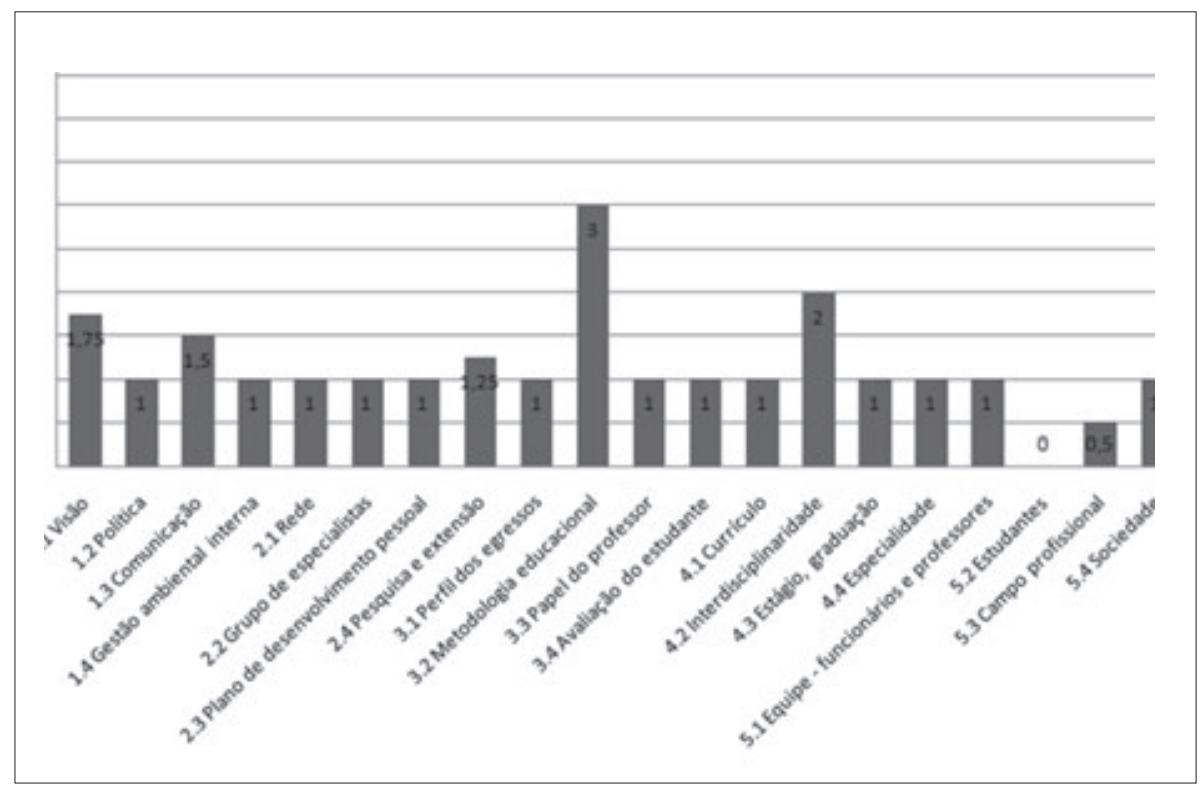


O critério interdisciplinaridade (4.2) atingiu o Estágio 2, o que representa que o currículo é estruturado de tal forma que os temas abordados pelas disciplinas são interligados. Nos demais critérios deste campo de atenção (4.1 currículo ; 4.3 estágio, graduação; 4.4 especialidade), foi alcançado o Estágio 1. Isto demonstra que analisar o critério interdisciplinaridade isoladamente, não permite dizer que o tema sustentabilidade seja abordado pelos cursos de maneira satisfatória.

O critério Visão (1.1) atingiu a mediana 1,75, o que demostra que a gestão tem uma visão sobre sustentabilidade, mesmo que implícita, pois oferece oportunidades para trabalhar com objetivos que podem estar além desta, gerando ações concretas para a universidade, embora sejam individuais. A existência de uma visão é importante, mas não gera necessariamente mudanças, ela representa apenas uma opinião. A Política (1.2) é a estrutura que gera a solidez dessa visão, pois proporciona a sua tradução em planos, e com isso metas são formuladas e esta atingiu a mediana 1.

O critério Gestão Ambiental Interna (1.4) apresentou nível de sustentabilidade 1 e deve receber uma atenção especial, pois executa um papel fundamental demonstrando o respeito que a instituição tem com o meio ambiente. A UPF possui vários programas e projetos de melhoramento da qualidade ambiental, porém, constituem-se como práticas isoladas já que a universidade não possui um Sistema de Gestão Ambiental (SGA). O que se propõe é a definição de um plano de ações que possibilitem o enquadramento da universidade em um Estágio 3, com práticas ambientais interligadas, onde existam uma política clara e pessoas responsáveis pelo planejamento, implementação, avaliação e ações de melhoria contínua.

O critério Estudantes (5.2) aborda a existência de dados na universidade sobre a percepção dos alunos em relação a sustentabilidade na Instituição. Como a universidade não dispõe de dados singificativos para a apreciação, os valores pontuados na avaliação deste critério foram baixos, resultando em um valor de mediana igual a zero.

As pontuações atribuídas para os critérios possibilitaram calcular uma mediana para cada campo de atenção. Neste contexto, a análise dos critérios em conjunto reflete melhor a realidade da Instituição do que quando analisados individualmente. A Figura 4 apresenta a mediana de cada campo de atenção e proporciona uma melhor compreensão da situação atual da universidade quanto à sustentabilidade. Observa-se que os valores das medianas dos campos de atenção ficaram entre 1,25 (1. Visão e Política) e 0,5 (5. Resultados da Avaliação), valores considerados baixos, que demonstram a falta de uma gestão 
integrada para universidade. Quando analisados de forma conjunta os critérios que se destacaram em alguns cursos na análise individual não são suficientes para elevar o conceito dos seus campos de atenção.

Figura 4 - Mediana do nível de Sustentabilidade dos campos de atenção AISHE para a UPF.

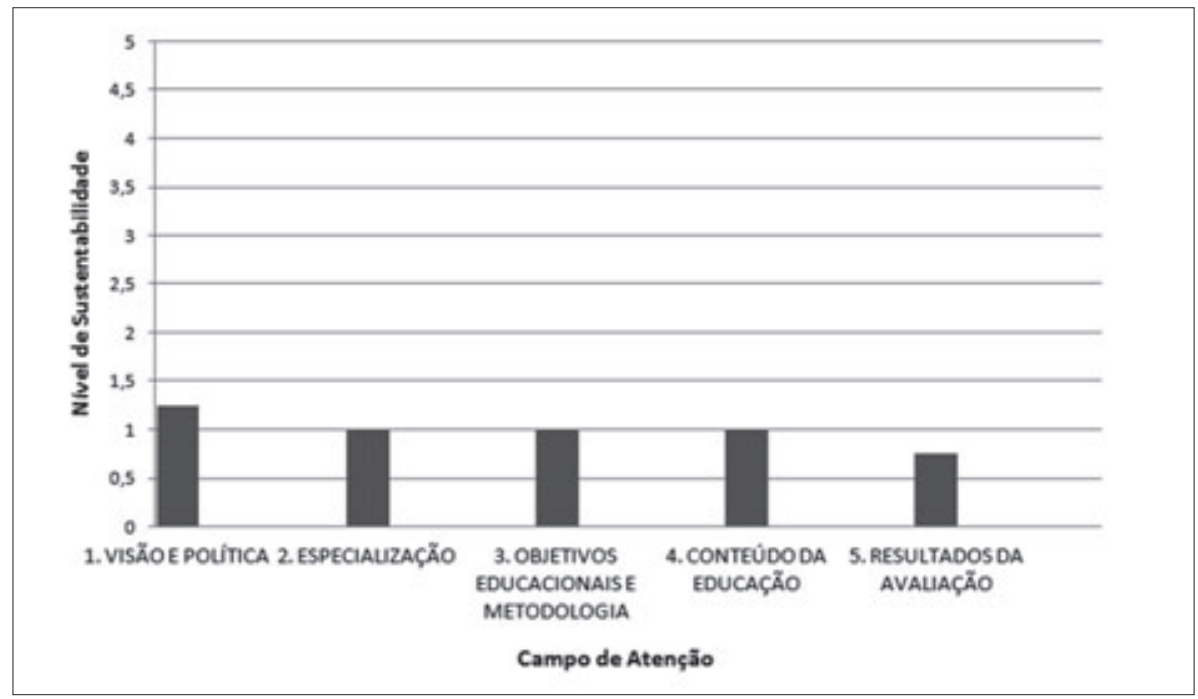

O campo de atenção Visão e Política foi o que atingiu o maior nível de sustentabilidade, demonstrando que a intenção e o planejamento para uma universidade sustentável existem na instituição. Além disto, este campo é o início do processo e por isto é esperado que seja o mais desenvolvido. Mesmo assim, seu valor mediano ainda é baixo, 1,25. Este campo é composto pelos critérios Visão, Política, Comunicação e Gestão Ambiental interna, e suas medianas foram apresentadas na Figura 3.

Análisando-se os demais campos de atenção, pode-se destacar o campo Resultados da Avalição (5) que obteve a pontuação mediana de 0,75 , valor considerado não representativo. No momento em que é constatado que não existe uma forte presença da sustentabilidade na universidade, não seria lógico que houvessem dados sobre uma avaliação da apreciação dos alunos, sociedade, professores e campo profissional. É mais interessante saber o que esses grupos desejam da UPF como uma universidade sustentável, do que avaliar as suas opiniões sobre a situação da sustentabilidade na instituição. 


\subsection{Avaliação da sustentabilidade nos cursos segundo os professores e alunos}

Para a avaliação da sustentabilidade segundo os professores foi aplicado um questionário apresentado na Figura 5. Dois professores de cada um dos cursos participantes da primeira etapa responderam ao questionário, que continha nove aspectos relacionados a questões de sustentabilidade, que estão presentes nos critérios AISHE. Os participantes deveriam pontuar de 0 a 3 cada um dos aspectos, sendo o significado dessa pontuação: 0 - não concordo; 1 - não concordo e nem discordo; 2 - concordo em parte; e 3 - concordo, essa pontuação foi denominada nível de percepção.

Figura 5 - Questionários aplicado aos professores para avaliação da sustentabilidade na UPF.

\begin{tabular}{|c|c|c|c|c|}
\hline ASPECTOS & $\begin{array}{l}\text { 응 } \\
\text { 홍 } \\
8 \\
8 \\
8 \\
\stackrel{9}{z}\end{array}$ & 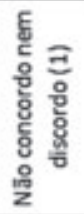 & 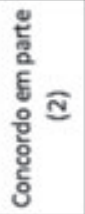 & $\begin{array}{l}\frac{\text { के }}{8} \\
\frac{8}{8} \\
\frac{8}{8}\end{array}$ \\
\hline \multicolumn{5}{|l|}{$\begin{array}{l}1 \text { - No rezimento da UPF são encontrados aspectos relacionados ao } \\
\text { desenvolvimento sustentóvel }\end{array}$} \\
\hline \multicolumn{5}{|l|}{$\begin{array}{l}2 \text { - As diretrizes para a gestão ambiental interna são bem observadas pelos } \\
\text { professores, funcionabrios e estudantes. }\end{array}$} \\
\hline \multicolumn{5}{|l|}{$\begin{array}{l}3 \text { - Alguns membros de nossa equipe (professores e funcionários) são } \\
\text { especialistas em desenvolvimento sustentável. }\end{array}$} \\
\hline \multicolumn{5}{|l|}{$\begin{array}{l}\text { 4- Eu estou bem informado sobre os aspectos da sustentabilidade ambiental } \\
\text { dentro da minha ärea de atuaşäo na universidade. }\end{array}$} \\
\hline \multicolumn{5}{|l|}{$\begin{array}{l}\text { 5-O curriculo dos cursos nos quais ensino contém aspectos suficientes } \\
\text { relacionados ao conhecimento sobre desenvolvimento sustentável. }\end{array}$} \\
\hline \multicolumn{5}{|l|}{$\begin{array}{l}\text { 6- Sustentabilidade amblental é muito mais do que uma especialidade: nós a } \\
\text { encaramos como algo amplo e interdisciplinar. }\end{array}$} \\
\hline \multicolumn{5}{|l|}{$\begin{array}{l}7 \text { - As atividade de pesquisa e extensão contribuem para o conhecimento e } \\
\text { experiència dos professores com relaç̧̄o a sustentabilidade. }\end{array}$} \\
\hline \multicolumn{5}{|l|}{$\begin{array}{l}8 \text { - Quando avalio projetos, atividades e provas, eu sempre considero aspectos } \\
\text { da sustentabilidade ambiental. }\end{array}$} \\
\hline $\begin{array}{l}\text { 9-Eu contribuo para a educaç̋̃o dos meus estudantes tornando-os cidadる̊os e } \\
\text { profissionais responsáveis. }\end{array}$ & & & & \\
\hline
\end{tabular}

A Figura 6 apresentada a porcentagem de professores que optou por não concordo, não concordo nem discordo, concordo em parte e concordo para cada um dos aspectos analisados. 
Figura 6 - Porcentagem de professores que optaram por cada um dos níveis de percepção para cada aspecto analisado.

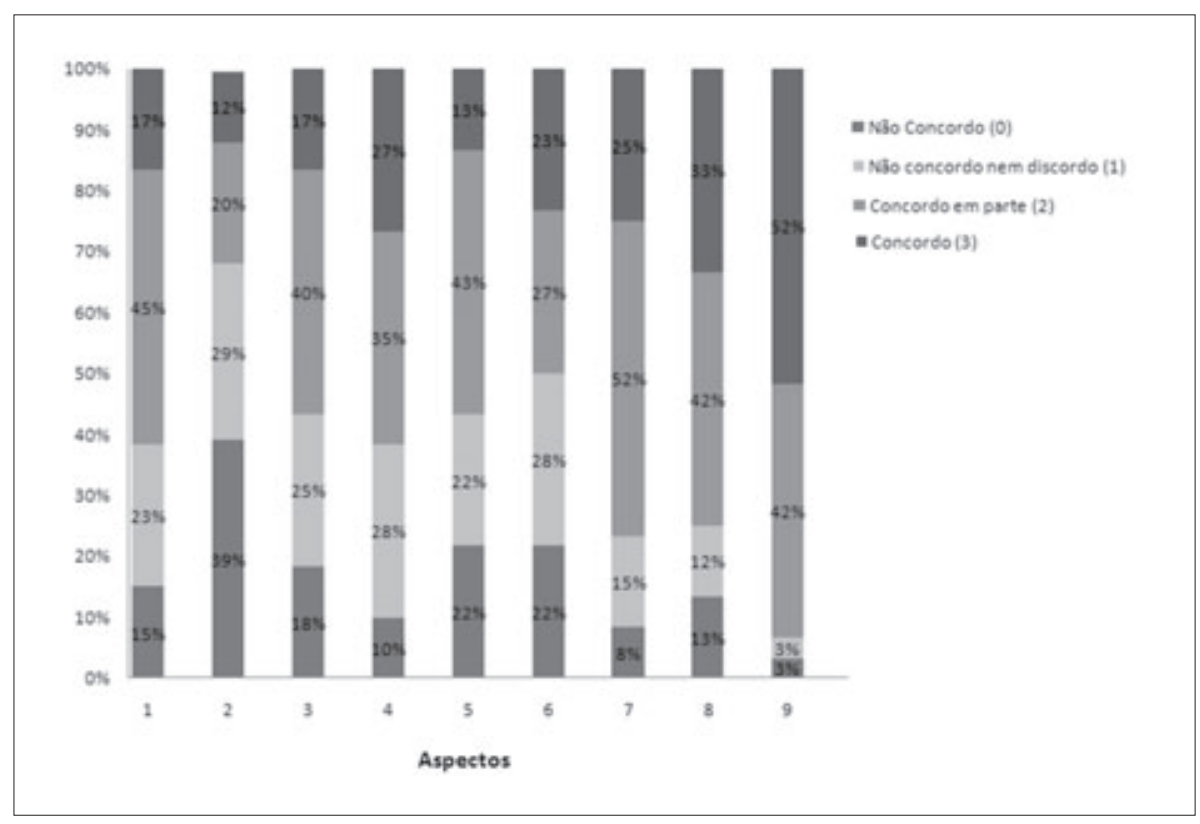

Os aspectos 1 e 2 estão relacionados não apenas com a presença de uma visão e política em prol da sustentabilidade na UPF por parte da instituição, mas com o conhecimento a respeito desse regimento por parte dos funcionários, alunos e professores. Dos professores entrevistados 45\% responderam que concordam em partes com a presença do desenvolvimento sustentável no regimento da instituição. Porém 39\% não concordam quanto à observância dessas diretrizes, mostrando que acreditam que uma parcela significativa dos funcionários, alunos ou mesmo professores, não valorizam e respeitam os princípios do desenvolvimento sustentável.

Quando é abordada não somente a existência de especialistas, mas também o conhecimento de aspectos relacionados a sustentabilidade na sua área de atuação, os professores consideram que tanto particularmente como os seus colegas, estão perto da excelência. Essa afirmação se justifica por $40 \%$ dos professores responderem concordo em parte com o aspecto 3 e a mesma resposta foi dada por $35 \%$ dos professores para o aspecto 4 , representando a maioria. Apesar de acreditarem que existem conhecimentos satisfatórios sobre sustentabilidade da parte de todos os professores, ela ainda 
não é considerada como algo amplo e interdisciplinar, pois o aspecto 6 que trata sobre esse tema obteve maior incidência de respostas para opção não concordo nem discordo (28\%). O aspecto 5 apresentou maior incidência da resposta concordo em parte, mostrando que o currículo dos cursos trás aspectos relacionados ao desenvolvimento sustentável, porém estes ainda não são suficientes. Esses resultados demonstram que a sustentabilidade ainda é encarada como uma especialidade e não como algo interdisciplinar nas instituições de ensino.

Quando tratamos da pesquisa e extensão, os professores acreditam que ela contribui significativamente para o conhecimento e experiência dos professores com relação a sustentabilidade, pois na sua grande maioria concordaram em partes com o aspecto 7. Esse foi o mesmo resultado obtido pelo aspecto 8 , mostrando que na maioria dos casos os professores consideram a presença de aspectos relacionados a sustentabilidade na hora de avaliarem trabalhos e provas dos estudantes.

O aspecto 9 relacionado a contribuição dos professores na formação dos estudantes, para que eles se tornem cidadãos e profissionais responsáveis, quanto ao desenvolvimento sustentável, foi o mais bem pontuado, 52\% dos professores concordam que isto esteja sendo feito e $42 \%$ concordaram em parte, resultando em um total de $94 \%$. Uma justificativa para os $42 \%$ dos professores que concordaram em parte seria que eles acreditam que o que vem sendo ensinado a respeito de sustentabilidade talvez não seja o ideal ou suficiente para capacitar os egressos e torná-los cidadãos sustentavelmente responsáveis. Indo de acordo com a concordância em parte demonstrada pelos professores quanto à presença do tema sustentabilidade no currículo dos cursos em que ensinam.

Um questionário nos mesmos moldes do aplicado para os professores foi aplicado para os alunos, ele está apresentado na Figura 7. Três alunos de cada um dos cursos participantes da primeira etapa responderam a este questionário.

A Figura 8 apresenta a porcentagem de alunos que optou por não concordo, não concordo e nem discordo, concordo em parte e concordo para cada um dos aspectos analisados.

Com relação à política da universidade, que se referem aos aspectos 1, 2 e 3, os alunos afirmam não concordar nem discordar quanto a tais afirmações, o que denota uma falta de conhecimento a cerca do que a universidade vem fazendo a respeito da sua sustentabilidade. No que diz respeito ao seu próprio conhecimento sobre sustentabilidade e a abordagem dada a este tema no seu 
Figura 7 - Questionários aplicado aos alunos para avaliação da sustentabilidade na UPF.

\begin{tabular}{|c|c|c|c|c|}
\hline Aspectos & $\begin{array}{l}\overline{5} \\
\text { 웅 } \\
8 \\
8 \\
8 \\
\stackrel{0}{z}\end{array}$ & 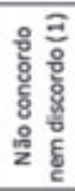 & 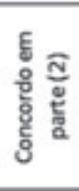 & $\begin{array}{l}\frac{\pi}{8} \\
\frac{8}{8} \\
\frac{8}{8}\end{array}$ \\
\hline \multicolumn{5}{|l|}{$\begin{array}{l}1 \text { - No regimento da UPF slo encontrados aspectos relacionados ao } \\
\text { desenvolvimento sustentivel. }\end{array}$} \\
\hline \multicolumn{5}{|l|}{$\begin{array}{l}2 \text { - As diretriaes para a cestä̀ ambiental interna săo bem observadas pelos } \\
\text { funcionbrios e estudantes. }\end{array}$} \\
\hline \multicolumn{5}{|l|}{$\begin{array}{l}3 \text { - Alguns dos meus professores sæ̃o especialistas em desenvolvimento } \\
\text { sustentável. }\end{array}$} \\
\hline \multicolumn{5}{|l|}{$\begin{array}{l}4 \text { - Estou bem informado sobre os aspectos de sustentabilidade ambiental } \\
\text { dentro da minha área de interesse e atuaş̋o. }\end{array}$} \\
\hline \multicolumn{5}{|l|}{$\begin{array}{l}\text { 5- O curriculo de meu curso contim aspectos suficientes de desenvolvimento } \\
\text { sustentivel. }\end{array}$} \\
\hline \multicolumn{5}{|l|}{$\begin{array}{l}\text { 6- Sustentabilidade ambiental é muito mais do que uma especialidade: nós a } \\
\text { encaramos como algo amplo e interdisciplinar. }\end{array}$} \\
\hline \multicolumn{5}{|l|}{$\begin{array}{l}\text { 7- } \ell \text { correto afirmar que os aspectos éticos são expressos de forma séria no } \\
\text { curriculo do meu curso. }\end{array}$} \\
\hline \multicolumn{5}{|l|}{$\begin{array}{l}\text { 8- Quando avaliam nossos projetos, atividades e provas, os professores } \\
\text { sempre consideram os aspectos da sustentabilidade ambiental. }\end{array}$} \\
\hline $\begin{array}{l}9 \text { - Quando eu me formar, estarei preparado para acir em prol da } \\
\text { sustentabilidade ambiental por meio do mev comportamento como } \\
\text { profissional. }\end{array}$ & & & & \\
\hline
\end{tabular}

Figura 8 - Porcentagem de alunos que optaram por cada um dos níveis de percepção para cada aspecto analisado

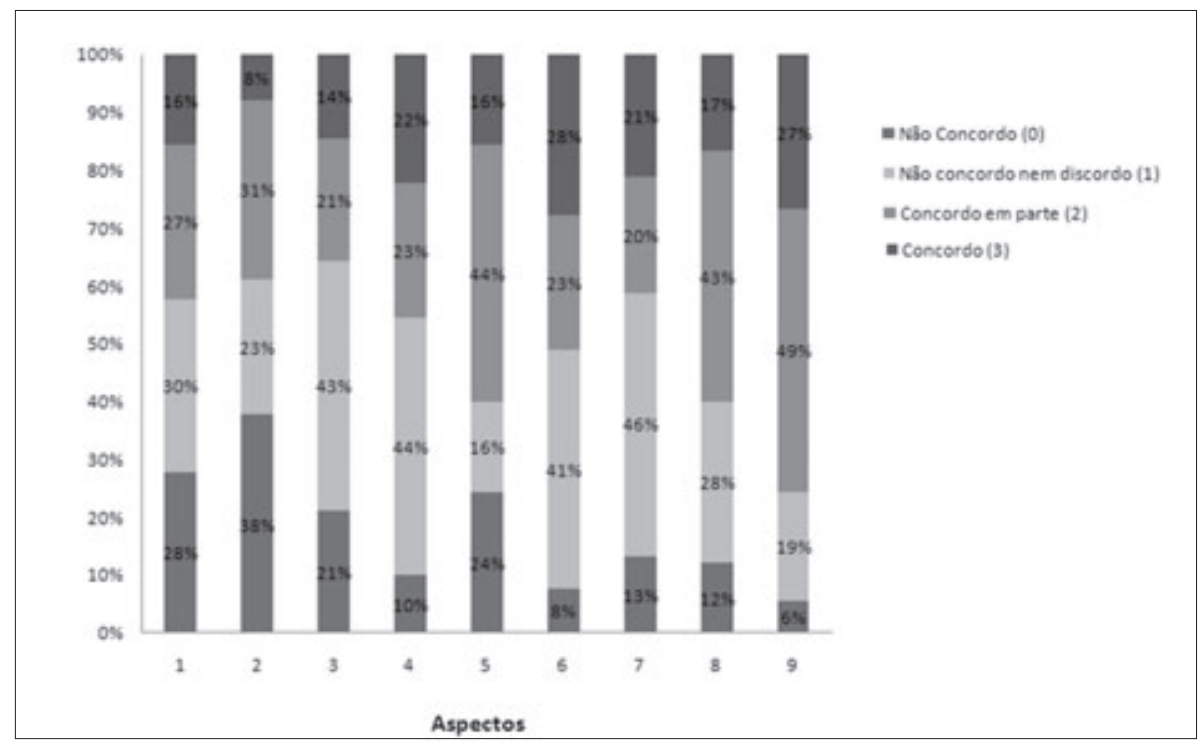


currículo, os alunos afirmam concordar em parte. Isto significa que este tema pode ser tratado de maneira mais efetiva em seu currículo e que também podem investir mais esforços próprios para compreender a sistemática da sustentabilidade, favorecendo o desenvolvimento de um censo ético mais aguçado em relação a sua atuação profissional futura de maneira sustentável.

No aspecto 4, a maioria, ou seja, 44\% também afirmam não concordar nem discordar quanto ao seu nível de conhecimento a respeito da sustentabilidade em relação a sua área de interesse. O aspecto 5, apresentou 44\% dos alunos concordando em parte que a sustentabilidade seja abordada de maneira satisfatória pelas disciplinas do currículo do seu curso, embora ainda não de forma ideal.

Com relação a interdisciplinaridade dos temas sobre sustentabilidade tratados no currículo, $41 \%$ dos alunos afirmam não concordar nem discordar, o que representa que consideram a sustentabilidade apenas como uma especialidade e não algo interdisciplinar. Mesmo destaque se dá para o aspecto 7 onde a maioria dos alunos, que corresponde a 46\%, afirmam não concordar nem discordar com a presença de aspectos éticos em relação a abordagem dada sobre sustentabilidade no currículo do seu curso. Tal posicionamento demonstra incerteza ou até mesmo falta de conhecimento por parte dos alunos sobre a relação entre a sustentabilidade e a estrutura currícular do curso.

Para o aspecto $8,43 \%$ dos alunos afirmam concordar em parte que os professores consideram a presença de aspectos relacionados à sustentabilidade na hora de avaliarem seus trabalhos e provas. O aspecto 9, que trata da percepção dos alunos quanto a sua postura profissional futura, apresentou os melhores resultados, pois $49 \%$ afirmam concordar em parte e $27 \%$ concordar que seu comportamento profissional será comprometido com a ética da sustentabilidade. Porém, isto também demonstra que a sustentabilidade pode ser revista, principalmente dentro do contexto curricular, para que ofereça maior segurança aos futuros egressos no que diz respeito ao que representa as atitudes sustentáveis em nosso meio.

\subsection{Comparação entre as respostas de coordenadores, professores e alunos}

O Quadro 4 apresenta as respostas dadas sobre as mesmas temáticas por coordenadores, alunos e professores. Permitindo dessa forma a sua comparação. 


\section{Quadro 4 - Comparação das respostas de coordenadores, alunos e professores.}

\begin{tabular}{|c|c|c|c|c|}
\hline Tembtica & $\begin{array}{c}\text { Critério } \\
\text { relaclonado }\end{array}$ & Coordenadores & Professores & Alunes \\
\hline $\begin{array}{l}\text { Existlencla da } \\
\text { sustentabilidade no } \\
\text { regimento da institulça.a. }\end{array}$ & 1.3 & $\begin{array}{l}\text { A sustentabilidade estí a } \\
\text { caminho de ser incluida no } \\
\text { regimento da UPF. }\end{array}$ & $\begin{array}{l}\text { Concordam em parte que a } \\
\text { sustentabilidade esta } \\
\text { presente no seu regimento. }\end{array}$ & $\begin{array}{l}\text { NDo concordam nem } \\
\text { discordam: indicio de falta } \\
\text { de conhecimeto sobre o } \\
\text { assunto. }\end{array}$ \\
\hline $\begin{array}{l}\text { Observlncia das diretrlzes } \\
\text { amblentals por } \\
\text { professones, funcliondirlos e } \\
\text { alunos. }\end{array}$ & 1.4 & $\begin{array}{l}\text { Aguns mebros da } \\
\text { comunidade acadtmica } \\
\text { prestam atencla }\end{array}$ & $\begin{array}{l}\text { NBo concordaram que as } \\
\text { diretrizes sejam } \\
\text { observadas. }\end{array}$ & $\begin{array}{l}\text { NDo concordaram que as } \\
\text { diretrises sejam observadas. }\end{array}$ \\
\hline $\begin{array}{l}\text { Existencia de especialistas } \\
\text { em desemolvimento } \\
\text { sustentbvel. }\end{array}$ & $2.2 \cdot 2.3$ & $\begin{array}{l}\text { A universidade possul poucos } \\
\text { especialistas e quando } \\
\text { existem é por iniciativa } \\
\text { prórpria. }\end{array}$ & $\begin{array}{l}\text { A universidade possul } \\
\text { poucos especialistas e } \\
\text { quando exlstem } 6 \text { por } \\
\text { inlciatlva prórprla. }\end{array}$ & $\begin{array}{l}\text { NLio concordam nem } \\
\text { discordame indicio de falta } \\
\text { de conhecimeto sobre o } \\
\text { assunto. }\end{array}$ \\
\hline $\begin{array}{l}\text { Nhel de informaçlo sobre } \\
\text { aspectos relacionados a } \\
\text { sustentailidade na área de } \\
\text { atuaç̃o. }\end{array}$ & 3.1 e 2.3 & $\begin{array}{l}\text { Consideram que os alunos } \\
\text { tem conhecimento de alguns } \\
\text { aspectos apenas relacionados } \\
\text { ao DS; jb os professores tem } \\
\text { conhecimento sobre o DS } \\
\text { devido a iniclativas } \\
\text { individuals. }\end{array}$ & $\begin{array}{l}\text { Concordam em parte que } \\
\text { tem conhecimentos sobre } \\
\text { DS. }\end{array}$ & $\begin{array}{l}\text { NDo cencordam nem } \\
\text { discordame NDo se } \\
\text { consideram informados de } \\
\text { maneira satisfatoria. }\end{array}$ \\
\hline $\begin{array}{l}\text { Presenca do DS no } \\
\text { cumiculo dos cursos. }\end{array}$ & $3.1 \times 4.1$ & $\begin{array}{l}\text { Acreditam que o assunto nJo } \\
\text { t trabalhado de maneira } \\
\text { satisfatórla, pols apenas } \\
\text { algumas matérias do curriculo } \\
\text { abordam o DS. }\end{array}$ & $\begin{array}{l}\text { Concordaram em perte } \\
\text { sobre a existéncla do DS } \\
\text { nos curriculos. }\end{array}$ & $\begin{array}{l}\text { Concordaram em parte sobre } \\
\text { e existtencia do DS nos } \\
\text { currículos. }\end{array}$ \\
\hline $\begin{array}{l}\text { VisJo do OS como algo } \\
\text { imterdisciplinar e nilo } \\
\text { apenas como } \\
\text { especialidade. }\end{array}$ & 3.2 e 4.2 & $\begin{array}{l}\text { Consideram que existe } \\
\text { interdiciplinaridade. }\end{array}$ & $\begin{array}{l}\text { NJo concordam nem } \\
\text { discordam: pode } \\
\text { representar um } \\
\text { desconhecimento do } \\
\text { conceito de } \\
\text { interdisciplinaridade no } \\
\text { tange o DS. }\end{array}$ & $\begin{array}{l}\text { NLo concordam nem } \\
\text { discordam: pode representar } \\
\text { um desconhecimento do } \\
\text { concelto de } \\
\text { interdisclplinaridade no } \\
\text { tange o DS. }\end{array}$ \\
\hline $\begin{array}{l}\text { Abordagem de aspectos } \\
\text { eticos em relasio ao OS. }\end{array}$ & 3.3 & $\begin{array}{l}\text { Apenas alguns professores } \\
\text { enfotizam a necessidade de } \\
\text { se ter atitudes sustentívels. }\end{array}$ & $\cdot$ & $\begin{array}{l}\text { NDio concordam nem } \\
\text { discordams acreditam que os } \\
\text { aspectos éticos nllo sejam } \\
\text { abordados satisfacriamente. }\end{array}$ \\
\hline $\begin{array}{l}\text { Contribuiclo da pesquisa e } \\
\text { extençlo universitíria no } \\
\text { conhecimento sobre DS. }\end{array} \mid$ & 2.4 & $\begin{array}{l}\text { Acreditam que algumas } \\
\text { atividades de pesquisa e } \\
\text { extenglo envolvem o DS. }\end{array}$ & $\begin{array}{l}\text { Concordam em parte, pois } \\
\text { nem todos estlo inseridos } \\
\text { nessas atlidiades, que } \\
\text { poderlam ter um número } \\
\text { mais expressiva. }\end{array}$ & - \\
\hline $\begin{array}{l}\text { Relevância dos aspectos } \\
\text { sobre DS nas avaliacoles. }\end{array}$ & 4.3 & $\begin{array}{l}\text { Acreditam que apenas alguns } \\
\text { projetos incluem elementos } \\
\text { do DS. }\end{array}$ & Concordam em parte. & Concordam em parte. \\
\hline $\begin{array}{l}\text { Capacitaçlo dos egressos } \\
\text { para atuar em prol do DS. }\end{array}$ & 3.3 e 5.2 & $\begin{array}{l}\text { Acreditam que nem todos os } \\
\text { professores enfatizam a } \\
\text { importalncla do DS na atuaçlo } \\
\text { proflssional. }\end{array}$ & $\begin{array}{l}\text { Concordam que estejam } \\
\text { preparando os egressos } \\
\text { para isso. }\end{array}$ & $\begin{array}{l}\text { Concordam em parte que } \\
\text { estejam sendo preparados. }\end{array}$ \\
\hline
\end{tabular}


A maior incidência de respostas dos alunos como não concordo nem discordo, demonstra uma falta de conhecimento sobre a realidade da universidade, bem como uma insegurança a cerca do seu posicionamento a respeito de tais aspectos. No caso dos professores os maiores percentuais foram atribuídos para concordo em parte e concordo, o que denota que por estarem mais envolvidos no dia a dia da instituição possuem maior conhecimento sobre as ações que estão sendo desenvolvidas.

Isso indica que apesar de a temática fazer parte do cotidiano dos professores e coordenadores ela não é abordada de forma satisfatória com o aluno, que não se sente completamente capaz de atuar em prol do desenvolvimento sustentável. Dessa forma, pode-se afirmar que o conhecimento não esta atingindo a parte mais importante do processo, o aluno, que é o principal agente de mudança, na medida em que ele será o novo profissional e futuro líder da sociedade.

Outra resposta em comum que é evidenciada pelos professores e coordenadores, é a questão de o conhecimento e especialização em assuntos relacionados à sustentabilidade partir de iniciativas individuais dos funcionários, não havendo um estimulo da instituição quanto a isto. Quanto à observância das diretrizes ambientais alunos e professores foram unanimes em dizer que estas não estão sendo observadas, apenas os coordenadores acreditam que em alguns casos isto acontece. Esse resultado é o reflexo da falta de uma política e sistema de gestão ambiental organizado, que fortaleça essas diretrizes e torne a sua observância algo natural a comunidade acadêmica.

\section{CONCLUSÃO}

O uso de indicadores é importante para avaliar o estágio da universidade com relação a sua sustentabilidade ambiental. No que diz respeito ao ensino, foco desta pesquisa, a Universidade de Passo Fundo apresenta muitas diferenças entre seus cursos, o que demonstra uma falta de visão estratégica na gestão da universidade sobre esta temática. Isto pode estar relacionado a falta de priorização do tema nas agendas da administração.

Há muita dispersão nas ações, alguns cursos praticam mais ações sustentáveis do que outros, e isto aparece claramente na visão dos coordenadores. Não se pode desconsiderar as especificidades de cada curso, isto é uma característica que tende a particularidades e pode justificar alguns resultados. No entanto, existem critérios que poderiam ter sido avaliados mais positivamente para todos, se houvesse um planejamento da universidade que definisse nos cursos meios para aprimorarem a sua sustentabilidade ambiental. 
Em relação a aplicação do AISHE, notou-se dificuldade de compreensão de certas terminologias usadas no questionário, o que corrobora com a critica da ferramenta já apontada por outros autores. No entanto, isto também pode estar atrelado a falta de familiaridade de algumas áreas sobre determinadas terminologias.

Quando é comparada a opinião de coordenadores, professores e alunos percebe-se que os professores foram os mais positivos dos três grupos avaliados, pois concordaram em parte com a maioria dos aspectos relacionados a presença da sustentabilidade na instituição. Já os alunos mostraram uma insegurança na hora de afirmar algo sobre a sustentabilidade da UPF, demonstrando uma falta de conhecimento sobre o tema ou mesmo sobre as ações que vem sendo desenvolvidas na universidade. Isso ficou claro, pois a maioria das respostas dos alunos foram não concordo nem discordo. A avaliação negativa em alguns pontos dos coordenadores pode ser explicada pelo fato de os critérios serem mais amplos que os aspectos. Estes são mais pontuais e relacionados com atitudes pessoais, tornando dessa forma os critérios mais dependentes de uma gestão que vai além do poder dos coordenadores.

\section{REFERÊNCIAS}

ADOMSSENT, M.; GODEMANN, J.; MICHELSEN, G. Transferability of approaches to sustainable development at universities as a challenge.

International Journal of Sustainability in Higher Education, Hamburgo, v. 8, n. 4, p. 385-402, 2007.

AISHE. Auditing Instrument for Sustainability in Higher Education. English text. Amsterdam, Dutch Committee on Sustainable Higher Education. December, 2001.

BRANDLI, L. B. et al. The Latin America Meeting of Sustainable Universities (I ELAUS): results and possibilities.In: ERSCP-EMSU CONFERENCE, 2010, Delft, The Netherlands.

FERREIRA, A. J. D.; LOPES, M. A. R.; MORAIS, J. P. F. Environmental management and audit schemes implementation as an educational tool for sustainability. Journal of Cleaner Production, Knoxville, v. 14, p. 973982, 2006. 
HALAC, R.; SCHILLER, S; VENTURINI, E.(2005). Sustainable universities: New knowledge and innovative actions. THE 2005 WORLD SUSTAINABLE BUILDING CONFERENCE, 2005, Tokyo. Proceedings. Tokyo, 2005. p. 2316-2322

GARCÍA, F. J. L. Sustainability in higher education: what is happening?. Journal of Cleaner Production, Knoxville, v. 14, p. 757-760, 2006.

LIDGREN, A.; RODHE, H.; HUISINGH, D. A systemic approach to incorporate sustainability into university courses and curricula. Journal of Cleaner Production, Knoxville, v. 14, p. 797-809, fev. 2006.

ROORDA, N. 2008. Assessment, policy development \& certification of education for sustainable development: AISHE 2.0. In: ENVIRONMENTAL MANAGEMENT OF SUSTAINABLE UNIVERSITIES - EMSU, 5, 2008, Barcelona. Conference contributions. Barcelona: UPC/UAB/RCE, 2008. p. 493-502.

ROORDA, N.; MARTENS P. Assessment and Certification of Higher Education for Sustainable Development, New Rochelle,. v.1, n.1, p. 41-56, 2008.

SHRIBERG, M. Institutional assessment tools for sustainability in higher education. International Journal of Sustainability in Higher Education, Hamburgo, v. 3, n. 3, p. 254-270, 2002.

TAUCHEN, J.; BRANDLI, L. L. A gestão ambiental em instituições de ensino superior: modelo para implantação em campus universitário. Gestão \& Produção, São Carlos, v. 13, n. 3, p. 503-515, set-dez, 2006.

VELAZQUEZ, L. et al. Sustainable university: what can be the matter? Journal of Cleaner Production, Knoxville, v. 14, p. 810-819, fev. 2006.

WEENEN, H. van. Towards a vision of a sustainable university. International Journal of Sustainability in Higher Education, Hamburgo, v. 1, n. 1, p. 20-34, 2000. 